\title{
Dynamic Model Study and Analysis of DME Auto-Thermal Steam Reforming Reaction
}

\author{
Yan Gao, Cong Li \\ Shanghai University of Engineering Science, Shanghai, China \\ Email:449284019@qq.com
}

Received 20 April 2015; accepted 24 May 2015; published 27 May 2015

Copyright (C) 2015 by authors and Scientific Research Publishing Inc.

This work is licensed under the Creative Commons Attribution International License (CC BY).

http://creativecommons.org/licenses/by/4.0/

c) (i) Open Access

\begin{abstract}
Through the study of the kinetics of dimethyl ether steam reforming reaction, a two-dimensional model of the reactor is established. At the same time, rate equations of simplified elementary reactions of DME steam reforming reaction are deduced by the mechanism of Langmuir-Hinshelwood, and the rate constants are obtained by correcting the pre-exponential factor of Arrhenius equation. Finally, the analog data of DME steam reforming reaction under a variety of conditions are obtained, and making a simulation diagram. The two-dimensional model is substantially correct because of the analog data more in line with a variety of knowledge.
\end{abstract}

\section{Keywords}

Dimethyl Ether (DME), Kinetic Model, The Reaction Rate, Reforming Reaction

\section{Introduction}

Dimethyl ether has the advantage of economy, security, and the sources of diversity, bound from the research stage to the industrial stage [1]. However, due to the engine of DME has a shortcoming of fire earlier, making it smaller work load range [2], while the hydrogen fuel cell and electric vehicles are being tested and toward industrialization in the world, but blocked in hydrogen storage technology [3], so automotive fuel reforming is an important way to solve the problem of the hydrogen energy [4] [5].

DME is an ideal vehicle fuel, but also has capability of chemical hydrogen storage. Therefore, many scholars have been studied to the DME reforming processes [6]-[8], confirming its value of commerce and scientific and finding some technical issues, such as the hydrogen yield. Generally speaking, the main method of DME reforming is the traditional methods and the plasma reforming method. The traditional methods include Auto- 
thermal reforming, steam reforming, partial oxidation reforming and so on. However, the study of kinetics model about DME reforming reaction is still relatively lacking in the current. Weiqi Qian et al. [9] used the quasi-steady method to establish a simplified chemical kinetic model for combustion of hydrocarbon fuels, effectively reducing the reaction components. Solution variables and differential equations are reduced when it is calculated in the flow field, improving the efficiency of calculation. Yumin Chen et al. [10] conducted kinetic analysis to the process of methane auto-thermal reforming reaction. Wang Feng et al. [11] conducted kinetic analysis to the process of methanol steam reforming in the micro-reactor. Dongmei Feng et al. [12] made the Kinetic Study of the process about dimethyl ether steam reforming reaction using of a catalyst $\mathrm{CuO}-\mathrm{ZnO}-$ $\mathrm{Al}_{2} \mathrm{O}_{3}+\mathrm{ZSM}-5$. This article will use the catalyst $\mathrm{Cu}-\mathrm{Ni} / \gamma-\mathrm{Al}_{2} \mathrm{O}_{3}$ to make kinetic studies of Dimethyl ether steam reforming reaction, establishing a two-dimensional model of the reactor, deducing the rate equation of simplified elementary reaction, learning the influence of the reaction rate and the mole fraction with temperature and time.

\section{Experimental Methods}

During the whole experiment, the space velocity of DME steam reforming reactor is $0.3 \mathrm{~m} / \mathrm{s}$. The molar ratio of water and DME is 1 to 3 . The feed mole fraction of dimethyl ether is between 5 and 15 . The flow rate of DME is $10^{-5} \mathrm{~mol} / \mathrm{s}$ in the feed mouth. The pressure inside the reactor is $0.1 \mathrm{Mpa}$ and the range of temperature is $200^{\circ} \mathrm{C}$ to $400^{\circ} \mathrm{C}$.

\section{The Kinetic Models}

\subsection{Reforming Reactor Model}

The kinetic model of DME steam reforming reactor applies to a two-dimensional model. Although the kinetic parameters of the reactor are difficult to be determined in the process of reaction, it can improve the accuracy of the change of amount of substance and energy conversion. The two-dimensional model is non-continuous, axial symmetry, similar to the two-dimensional reactor of Groppi, G. et al. [13]. The reaction of DME and $\mathrm{H}_{2} \mathrm{O}$ on the catalyst coating layer of the reactor produced $\mathrm{H}_{2}$ and oxides of carbon. In the course of the reaction, the mass of reactants and product are equal, the mass conservation equation as follows:

$$
\frac{\mathrm{d} w_{i}}{\mathrm{~d} z} m_{t} R T=S_{c} S_{v} k_{c} P_{t} M_{i}\left(Y_{i s}-Y_{i g}\right)
$$

Because the reactants are gas and in the high-speed motion in the reactor, and so axial diffusion of the gas mass is negligible. Because the heat exchanger conduit wall can isolate gas, so the radial diffusion of the gas mass in the reactor is also negligible. Then the above equation can be simplified to as follows:

$$
\rho_{a} R T \sum v_{i} r_{j s}=S_{v} k_{c} P_{t}\left(Y_{i s}-Y_{i g}\right)
$$

Further, on the catalyst coating layer of the reactor, the mass conservation equation of each element in the course of the reaction and diffusion is as follows:

$$
\frac{\mathrm{d}^{2} Y_{i c}}{\mathrm{~d} x^{2}}=-\left(\sum v_{i} r_{j}\right) \frac{\rho_{c} R T_{s}}{P_{t} D_{e}}
$$

In this reactor, if the catalyst coating layer is a uniformly thickness, the boundary conditions are shown in Table 1. The average thickness of the catalyst coating layer is about 35 microns, while the effective diffusion coefficient $D_{e}\left(\mathrm{~m}^{2} \cdot \mathrm{s}^{-1}\right)$ is estimated by random pore model [14]. On the catalyst coating layer, according to the mass conservation of the elements, the average reaction rate $r_{j s}$ can be obtained:

$$
r_{j s}=\frac{\int_{0}^{t_{c}} r_{j} \mathrm{~d} x}{t_{c}}
$$

Similar to the gas phase mass balance of (2), axial and radial dispersions were neglected in the gas-phase heat balance: 
Table 1. Boundary conditions for the 2D monolithic reactor wash-coat mass balance and solid heat balance.

\begin{tabular}{cc}
\hline Position & Boundary conditions \\
\hline$x=0$ (Catalyst coating surface) & $Y_{i c}=Y_{i s}$ \\
$\frac{\mathrm{d} Y_{i c}}{\mathrm{~d} x}=0$ \\
$Z=0$ (Inlet) $\quad$ (Catalyst coating boundary) \\
$Z=L$ (outlet) & $\mathrm{d} T_{s} / \mathrm{d} z=\varepsilon_{m} \sigma\left(T_{s}^{4}-T_{g}^{4}\right) /\left(\lambda_{s}-\varepsilon \lambda_{s}\right)$ \\
$r=0$ (monolith center) & $\mathrm{d} T_{s} / \mathrm{d} z=0$ \\
$r=R$ (monolith outer edge) & $\mathrm{d} T_{s} / \mathrm{d} r=0$ \\
$\mathrm{~d} T_{s} / \mathrm{d} r=\left(T_{w}-T_{s}\right) / x$
\end{tabular}

$$
\frac{\mathrm{d} T_{g}}{\mathrm{~d} z} m_{t} \sum_{i} \frac{w_{i}}{M_{i}} c_{p i}=S_{c} S_{v} h\left(T_{s}-T_{g}\right)
$$

External energy transfers to DME and water using of the heat conduction manner of the axial and radial through the reactor wall and the catalyst coating layer, using the equation:

$$
\frac{\mathrm{d}^{2} T_{s}}{\mathrm{dz}^{2}}+\frac{\mathrm{d}^{2} T_{s}}{\mathrm{~d} r^{2}}+\frac{1}{r} \frac{\mathrm{d} T_{s}}{\mathrm{~d} r}+\frac{\rho_{a}\left(\sum r_{j s}\left(-\Delta H_{R j}\right)\right)}{(1-\varepsilon) \lambda_{s}}=\frac{S_{v} h\left(T_{s}-T_{g}\right)}{(1-\varepsilon) \lambda_{s}}
$$

Wherein, $m_{t}$-The total mass flow rate $\left(\mathrm{kg} \cdot \mathrm{s}^{-1}\right), \mathrm{M}-$ Molar mass $\left(\mathrm{kg} \cdot \mathrm{mol}^{-1}\right), P_{t}$ - The total pressure $(\mathrm{Pa}), S_{c}$-Reactor cross-sectional area $\left(\mathrm{m}^{2}\right), R-\left(8.314 \mathrm{~Pa} \cdot \mathrm{m}^{3} \cdot \mathrm{mol}^{-1} \cdot \mathrm{K}^{-1}\right), t_{c}$-Catalyst coating thickness (m), $S_{v}$-Catalyst coating surface of the unit volume $\left(\mathrm{m}^{2} \cdot \mathrm{m}^{-3}\right), z$-The axial distance $(\mathrm{m}), R$ - Radial heat transfer coefficient, $\varepsilon$-Reactor porosity, $\varepsilon_{m}$-Emissivity, $\sigma-\left(5.67 \times 10^{-8} \mathrm{~W} \cdot \mathrm{m}^{-2} \cdot \mathrm{K}^{-4}\right)$, $\lambda_{s}$ - effective thermal conductivity $\left(\mathrm{W} \cdot \mathrm{m}^{-1} \cdot \mathrm{K}^{-1}\right), V$-Stoichiometric coefficients, $c$-Inside catalyst coating, $g$-gas, $x$-Axial distance, $Y$-Mole fraction, $i$-Species index, $j$-Response index, $h$-Heat transfer coefficient $\left(\mathrm{W} \cdot \mathrm{m}^{-2} \cdot \mathrm{K}^{-1}\right), \Delta H_{R}$-Reaction enthalpy $\left(\mathrm{J} \cdot \mathrm{mol}^{-1}\right), \quad k_{c}$-Mass transfer coefficient $\left(\mathrm{m} \cdot \mathrm{s}^{-1}\right), w$-Reactor wall, $s$-Catalyst coating surface, $w$-Mass fraction. Table 1 shows the boundary conditions of conservation of energy and the quality of the reactor model catalyst coating.

\subsection{Kinetics Model of DME Steam Reforming Reaction}

There are three major reactions in the process of DME steam reforming [15], which can be shown in Table 2, and DME oxidation reaction is the heat source. In the ideal case, the inlet of reactor is water, DME and $\mathrm{O}_{2}$, and the outlet is $\mathrm{CO}_{2}$ and $\mathrm{H}_{2}$. When each elementary reaction is in a relatively stable state of the reaction rate, adsorption equilibrium constant of $\mathrm{H}_{2}$ and $\mathrm{CO}_{2}$ on the catalyst is relatively small, and it can be ignored as the case in the calculation process. The reaction rate equation takes Langmuir-Hinshelwood model of water molecules and other molecules competitive adsorption, and it is ideal for surface reaction.

\subsection{Parameters of the Kinetic Model}

Arrhenius equation is used to solve the rate constants, and the expression is:

$$
k=A \mathrm{e}^{-\frac{E}{R T}}
$$

Due to the range of experimental temperature is $200^{\circ} \mathrm{C}$ to $400^{\circ} \mathrm{C}$, so temperature variation range is small, and the pre-exponential factor $A$ is corrected and the activation energy not, then Arrhenius equation:

$$
k_{j}=A_{s_{j}} \mathrm{e}^{-\frac{E_{A_{j}}}{R T}}
$$

where, $k_{j}\left(\mathrm{~mol} \cdot \mathrm{kg}^{-1} \cdot \mathrm{s}^{-1}\right)$ is the rate constant at temperature $T$. 
Then, the activation energy $E_{A}\left(\mathrm{~J} \cdot \mathrm{mol}^{-1}\right)$ can be considered as it of the initial temperature $T_{s_{j}}\left(200^{\circ} \mathrm{C}\right)$ and unchanged in the whole calculation process. The pre-exponential factor $A_{s_{j}}$ is calculated as follows:

$$
A_{s_{j}}=\frac{k_{s_{j}}}{\mathrm{e}^{-\frac{E_{A_{j}}}{R T_{s_{j}}}}}
$$

The fitting parameter of Adsorption equilibrium constant $\left(K_{j}\right)$ comprises of $K_{m j}$ of average temperature $\left(300^{\circ} \mathrm{C}\right)$ and adsorption enthalpy $\left(\Delta H_{a d s j}\right)$, and its expression is as follows:

$$
K_{j}=K_{m j} \exp \left(\frac{\Delta H_{a d s j}}{R}\left(\frac{1}{T_{m}}-\frac{1}{T}\right)\right)
$$

The main elementary reaction rate constant can be obtained by Equation (8) and (9) using ofrate constant $k_{s_{j}}$ and activation energy $E_{A_{j}}$ in the Table 3 [16]. While adsorption equilibrium constant $\left(K_{j}\right)$ of any temperature can be known by formula (10) using of $K_{m j}$ and the adsorption enthalpy $\left(\Delta H_{a d s j}\right)$ in Table 3. Finally, the rate formula of major elementary reactions in Table 2 can be computed for getting a variety of data.

\section{Results and Discussion}

The legend of all graphics is the same with the legend of Figure 1(a).

\begin{tabular}{|c|c|c|c|c|}
\hline Reaction Name & \multicolumn{2}{|c|}{ Chemical equation } & \multicolumn{2}{|c|}{ The reaction rate } \\
\hline $\begin{array}{l}\text { DME oxidation } \\
\text { reaction }\end{array}$ & \multicolumn{2}{|c|}{$\mathrm{CH}_{3} \mathrm{OCH}_{3}+3 \mathrm{O}_{2} \rightarrow 2 \mathrm{CO}_{2}+3 \mathrm{H}_{2} \mathrm{O}$} & \multicolumn{2}{|c|}{$r_{1}=\frac{k_{1} y_{\mathrm{DME}} y_{\mathrm{O}_{2}}}{\left(1+K_{\mathrm{H}_{2} \mathrm{O}} y_{\mathrm{H}_{2} \mathrm{O}}\right)^{2}}$} \\
\hline DME hydrolysis & \multicolumn{2}{|c|}{$\mathrm{CH}_{3} \mathrm{OCH}_{3}+\mathrm{H}_{2} \mathrm{O}(\mathrm{g}) \rightarrow 2 \mathrm{CH}_{3} \mathrm{OH}$} & \multicolumn{2}{|c|}{$r_{2}=\frac{k_{2} y_{\mathrm{DME}} y_{\mathrm{H}_{2} \mathrm{O}}}{\left(1+K_{\mathrm{H}_{2} \mathrm{O}} y_{\mathrm{H}_{2} \mathrm{O}}\right)^{2}}$} \\
\hline $\mathrm{CH}_{3} \mathrm{OH}$ decomposition & \multicolumn{2}{|c|}{$\mathrm{CH}_{3} \mathrm{OH} \rightarrow \mathrm{CO}+2 \mathrm{H}_{2}$} & \multicolumn{2}{|c|}{$r_{3}=\frac{k_{3} y_{\mathrm{CH}_{3} \mathrm{OH}}}{1+K_{\mathrm{H}_{2} \mathrm{O}} y_{\mathrm{H}_{2} \mathrm{O}}}$} \\
\hline Water-gas shift & \multicolumn{2}{|c|}{$\mathrm{H}_{2} \mathrm{O}+\mathrm{CO} \leftrightarrow \mathrm{CO}_{2}+\mathrm{H}_{2}$} & $r_{4}=\frac{k_{4} y_{\mathrm{CO}} y_{\mathrm{H}_{2} \mathrm{O}}}{\left(1+K_{\mathrm{H}_{2} \mathrm{O}} y_{\mathrm{H}_{2} \mathrm{O}}\right)^{2}}$ & $\left(1-\frac{y_{\mathrm{CO}_{2}} y_{\mathrm{H}_{2} \mathrm{O}}}{y_{\mathrm{CO}} y_{\mathrm{H}_{2} \mathrm{O}} K_{e q}}\right)$ \\
\hline Reaction type & Parameters & The value & Confidence intervals & Unit \\
\hline \multirow{2}{*}{ DME oxidation reaction } & $k_{s_{1}}$ & 53.5 & \pm 6 & $\mathrm{~mol} \cdot \mathrm{kg}^{-1} \cdot \mathrm{s}^{-1}$ \\
\hline & $E_{A_{1}}$ & 104.1 & \pm 5 & $\mathrm{~kJ} \cdot \mathrm{mol}^{-1}$ \\
\hline \multirow{2}{*}{ DME hydrolysis } & $k_{s_{2}}$ & 60.00 & \pm 14.03 & $\mathrm{~mol} \cdot \mathrm{kg}^{-1} \cdot \mathrm{s}^{-1}$ \\
\hline & $E_{\mathrm{A}_{2}}$ & 173.53 & \pm 24.01 & $\mathrm{~kJ} \cdot \mathrm{mol}^{-1}$ \\
\hline \multirow{2}{*}{$\mathrm{CH}_{3} \mathrm{OH}$ decomposition } & $k_{s_{3}}$ & 135.42 & \pm 29.75 & $\mathrm{~mol} \cdot \mathrm{kg}^{-1} \cdot \mathrm{s}^{-1}$ \\
\hline & $E_{A_{3}}$ & 107.36 & \pm 44.5 & $\mathrm{~kJ} \cdot \mathrm{mol}^{-1}$ \\
\hline \multirow{2}{*}{ Water-gas shift } & $k_{s_{4}}$ & 356.19 & \pm 170.4 & $\mathrm{~mol} \cdot \mathrm{kg}^{-1} \cdot \mathrm{s}^{-1}$ \\
\hline & $E_{A_{4}}$ & 180.84 & \pm 25.3 & $\mathrm{~kJ} \cdot \mathrm{mol}^{-1}$ \\
\hline \multirow{2}{*}{ Adsorption reaction water } & $K_{m}$ & 3.88 & 1.15 & $\mathrm{~mol} \cdot \mathrm{L}^{-1}$ \\
\hline & $\Delta H_{a d s}$ & -31.71 & 0.72 & $\mathrm{~kJ} \cdot \mathrm{mol}^{-1}$ \\
\hline
\end{tabular}

Table 2. Kinetic model overall reactions and rate expression. 


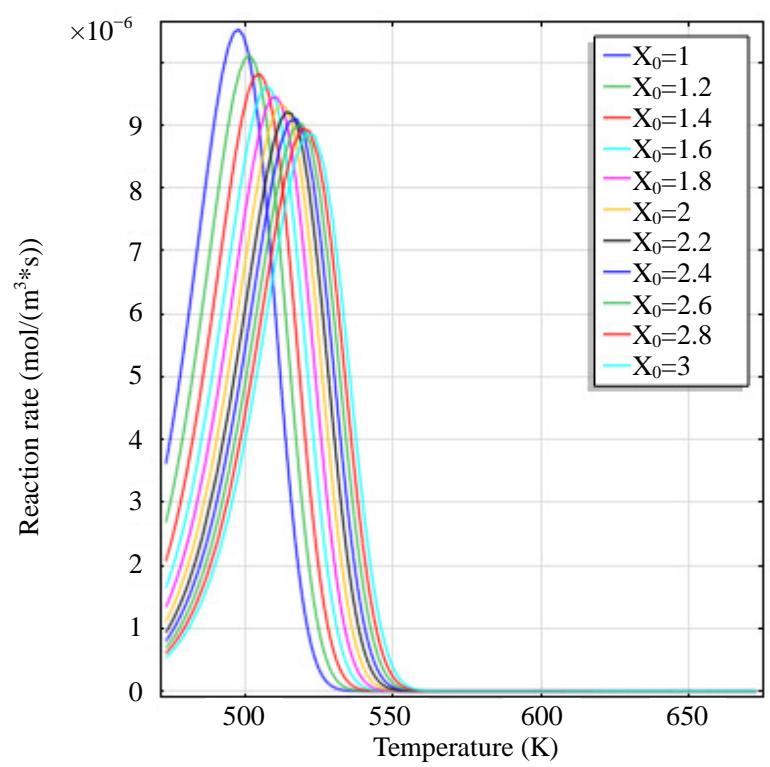

(a)

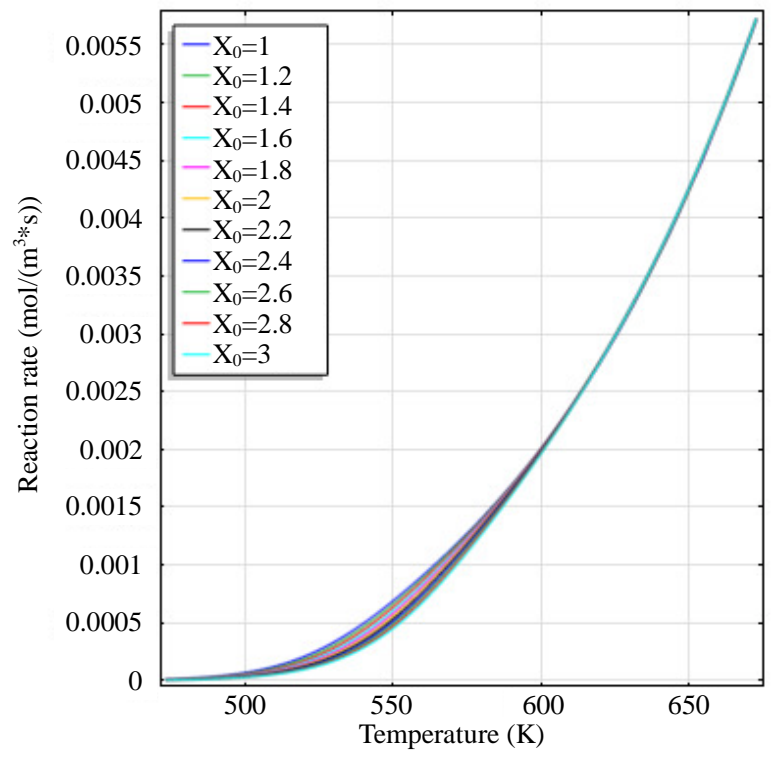

(c)

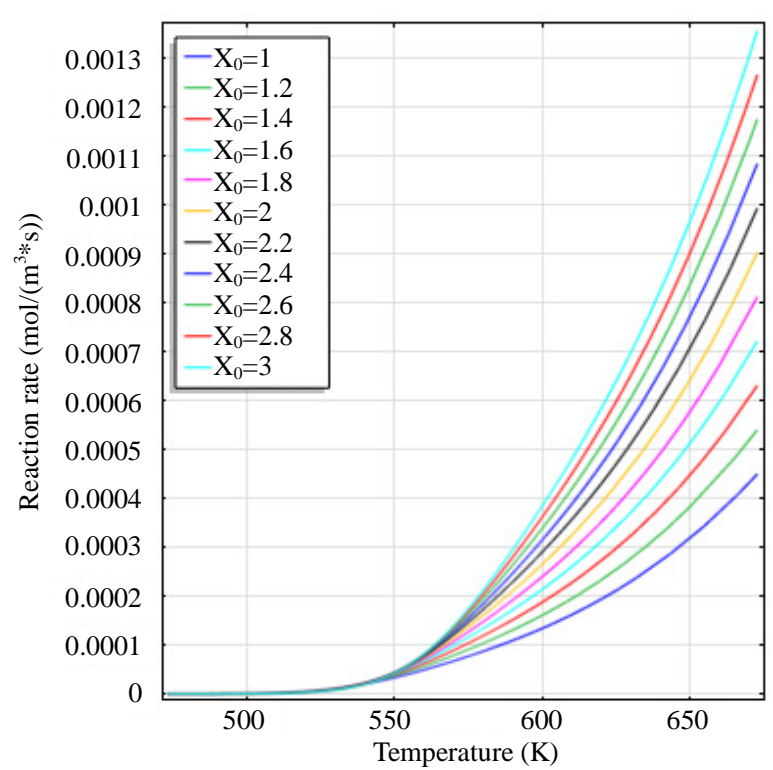

(b)



(d)

Figure 1. (a) The variation diagram of $r_{1}$ and temperature; (b) The variation diagram of $r_{2}$ and temperature; (c) The variation diagram of $r_{3}$ and temperature; (d) The variation diagram of $r_{4}$ and temperature.

Figure 1 is the graph of rate variation of each reaction, and the equation of temperature changing with time is $473+200 t$. Figure 1(a) is the variation diagram of rate and temperature for the oxidation reaction of DME, with increasing temperature, $r_{1}$ first adding and then reduced. The $r_{1}$ reduces due to insufficient of $\mathrm{O}_{2}$, so it can guarantee the hydrogen yield. Figure $\mathbf{1}(\mathbf{b})$ is rate-temperature diagram of DME hydrolysis reaction, and $r_{2}$ increases with increasing temperature, while it increases with ratio of water and DME $\left(X_{0}\right)$, indicating that this reaction is an endothermic reaction. Figure 1 (c) is rate-temperature diagram of $\mathrm{CH}_{3} \mathrm{OH}$ decomposition reaction, and $r_{3}$ increases with increasing temperature. Figure $\mathbf{1}(\mathbf{d})$ is rate-temperature curve of water-gas reaction, and $r_{4}$ increases with increasing temperature and $X_{0}$. From Figure 1 , at $550 \mathrm{~K}, r_{1}$ reducing to near $0, r_{2}$ and $r_{4}$ beginning to rapidly increase, $r_{2}$ being moment of greatest impact by $X_{0}$, this indicates DME reacts with $\mathrm{O}_{2}$ preferentially and it will quickly decompose and produce $\mathrm{H}_{2}$ in case of lack of oxygen and sufficient energy. 
When $r_{1}$ rises or $\mathrm{O}_{2}$ is enough, $r_{2}, r_{3}$ and $r_{4}$ basically keep zero. When $r_{1}$ reaches the maximum, DME begins to decompose and produce $\mathrm{CH}_{3} \mathrm{OH}$ and it has decomposed at the same time. In short, the ratio of water-DME and the ratio of oxygen-DME are important step of controlling the hydrogen yield.

Figure 2(a) is the molar flow rate variation graph of $\mathrm{H}_{2}$ with time, which rapidly increases to stabilize with increasing time, and it increases with increasing $X_{0}$ at the same time. Figure 2(b) is the molar flow rate variation graph of DME with time, which rapidly declines to stabilize with increasing time and it reduces with increasing $X_{0}$ at the same time. Figure 2(c) is the mole fraction graph of $\mathrm{H}_{2}$ with temperature variation, which increases with increasing temperature, and it is reduced at the same temperature with increasing $X_{0}$. Figure 2(d) is the mole fraction curve of DME with temperature variation, and the mole fraction decreases with increasing temperature. According to Figure 2(c) and Figure 2(d), at $550 \mathrm{~K}$, the mole fraction derivative of DME



(a)

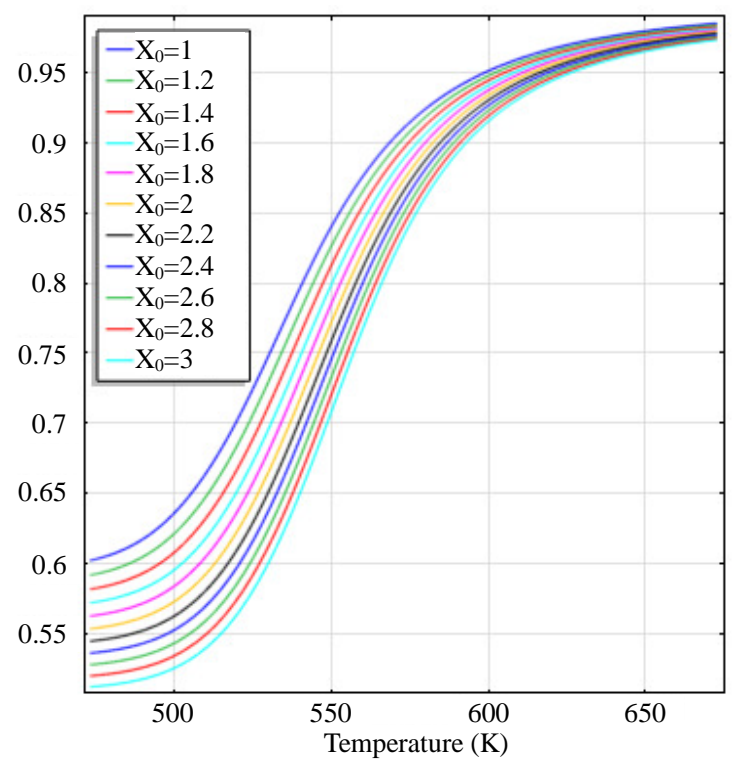

(c)

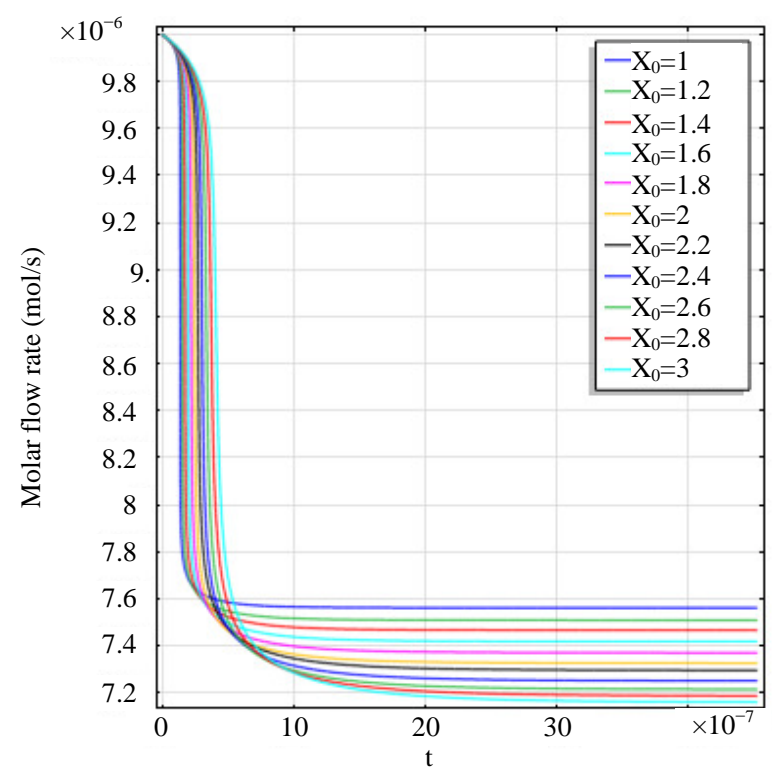

(b)

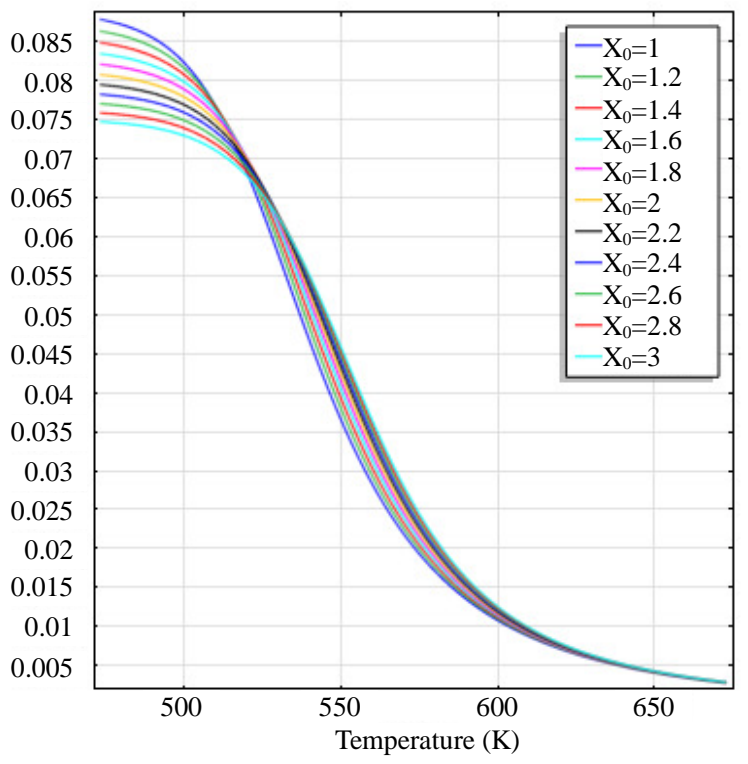

(d)

Figure 2. (a) The molar flow rate variation graph of $\mathrm{H}_{2}$ with time; (b) The molar flow rate variation graph of DME with time; (c) The mole fraction graph of $\mathrm{H}_{2}$ with temperature variation; (d) The mole fraction graph of DME with temperature variation. 
and $\mathrm{H}_{2}$ to temperature is the maximum, indicating that their speed of response here has a jump, which can be proven from Figure 1(b), Figure 1(c) and Figure 1(d). When the curve of Figure 2(a) and Figure 2(b) trend to steady, the curve of Figure 2(c) and Figure 2(d) are becoming more stable, indicating that the reactants at the inlet of the reactor achieves to conditions optimally. That is, if this state is changed, the reactants conditions of the reactor at the inlet need to change.

\section{Conclusion}

The two-dimensional model is substantially correct because of the analog data more in line with a variety of knowledge. For example, the ratio of water-DME and the ratio of oxygen-DME are important step of controlling the hydrogen yield. Finally, this article can provide important theoretical references to the kinetics of dimethyl ether steam reforming reaction.

\section{References}

[1] Yu, Y.-F. and Jing, Y.-H. (2010) The Research Analysis of the Application of the Vehicle DME Fuel. Northwest Coal, 6.

[2] Shudo, T. and Yamada, H. (2007) Hydrogen as an Ignition-Controlling Agent for HCCI Combustion Engine by Suppressing the Low-Temperature Oxidation. International Journal of Hydrogen Energy, 32, 3066-3072. http://dx.doi.org/10.1016/j.ijhydene.2006.12.002

[3] Sun, D.-L. (2011) Development and Challenge for On-Board Hydrogen Storage. Chinese Journal of Nature, 33, 13-18.

[4] Zhang, W.G., Lu, W.D. and Yan, Y. (2010) Experiment on the Performance of Steam Reforming by Dimethyl Ether. Transactions of the Chinese Society for Agricultural Machinery, 41, 6-16.

[5] Ji, C.W., Ju, B.J. and Dai, X.X. (2013) Mixed Combustion Performance Experiment of Syngas Produced by Ethanol Steam Reforming for Engine. Transactions of the Chinese Society for Agricultural Machinery, 44, 27-32.

[6] Feng, D.M., Wang, J.F. and Wang, D.Z. (2007) Production of Hydrogen from Dimethyl Ether over Catalysts. Sciencepaper Online.

[7] Li, C., Wang, Y.S. and Fan, P.Q. (2012) Numerical Analysis and Experimental Study of Hydrogen Production from Dimethyl Ether Steam Reforming. Science China Chemistry, 9.

[8] Zheng, Z.L. and Li, S.L. (2013) Thermodynamics Analysis of Hydrogen Production in Vehicle DME Steam Reforming Reaction System. Transactions of the Chinese Society for Agricultural Machinery, 9.

[9] Qian, W.-Q., Yang, S.-H., Xiao, B.-G. and Le, J.-L. (2007) Development of Reduced Chemical Reaction Kinetic Model for Hydro-Carbon Fuel Combustion with Quasi-Steady-State Approximation Method. Acta Aerodynamica Sinica, 3.

[10] Chen, Y.-M., Zhao, Y.-C., et al. (2011) Thermodynamic and Kinetic Analyses for Hydrogen Production via Methane Autothermal Reforming. Journal of Fuel Chemistry and Technology, 8.

[11] Wang, F., Zhou, J., Wang, G.J. and Zhou, X.J. (2011) Kinetics Study of Methanol Steam Reforming Hydrogen Production in a Microreactor. Acta Aerodynamica Sinica, 4.

[12] Feng, D.M., Wang, Y.Y., Wang, D.Z. and Wang, J.F. (2009) Steam Reforming of Dimethyl Ether over $\mathrm{CuO}-\mathrm{ZnO}-\mathrm{Al}_{2} \mathrm{O}_{3}+\mathrm{ZSM}-5$ : A Kinetic Study. Chemical Engineering Journal, 2.

[13] Groppi, G. and Tronconi, E. (2001) Simulation of Structured Catalytic Reactors with Enhanced Thermal Conductivity for Selective Oxidation Reactions. Catalysis Today, 69, 63-73. http://dx.doi.org/10.1016/S0920-5861(01)00356-X

[14] Froment, G.F. and Bischoff, K.B. (1990) Chemical Reactor Analysis and Design. 2nd Edition, John Wiley \& Sons, New York.

[15] Daubert, T.E. and Danner, R.P. (1989) Physical and Thermodynamic Properties of Pure Chemicals (Data Compilation). Hemisphere Publishing Corporation, New York.

[16] Creaser, D. and Creaser, D. (2010) Kinetic Modeling of Autothermal Reforming of Dimethyl Ether. Industrial Engineering Chemistry Research, 49, 9712-9719. 